\title{
Just how much of what we taste derives from the sense of smell?
}

\author{
Charles Spence ${ }^{1,2}$
}

\begin{abstract}
It is frequently asserted that somewhere between 75 and $95 \%$ of what we commonly think of as taste actually comes from the sense of smell. However, empirical evidence in support of such a precise-sounding quantitative claim is rarely, if ever, cited. Indeed, a closer look at the study that appears to have given rise to statements of this general type simply does not support the claim as made. As we will see, the often confused, and certainly confusing, use of the term "taste" - sometimes in the layman's everyday sense of flavour and, at other times, in the more precise scientific meaning of gustation, adds to the difficulty here. Furthermore, the widespread disagreement concerning which senses should be considered as constitutive of flavour perception and which merely modulatory means that it is probably not going to be possible to provide an exact answer to the question of how much of what people commonly think of as taste actually comes from the nose, until one has carefully defined one's terms. Even then, however, the answer is likely to vary quite markedly depending upon the particular combination of olfactory and gustatory stimuli that one is thinking about. Nevertheless, despite the difficulty associated with generating a precise value, or even range of values, most researchers would appear to agree that olfaction plays a "dominant" role in the tasting of food. This important observation (just without the precise-sounding percentages attached) certainly deserves to be shared more widely. Crucially, the evidence suggests that it can sometimes inspire the modernist chefs, not to mention the culinary artists and designers, to change the way in which they deliver multisensory flavour experiences to their customers (in order to capitalize on olfaction's often dominant role in our perception of food and drink).
\end{abstract}

Keywords: Taste, Flavour, Olfaction, Multisensory, Integration

"To which of our senses are we most indebted for the pleasures of the table? To name the sense of taste in answer to this question would be quite as incorrect as to assert that we go to the opera to please our eyes. More incorrect, in fact, because many do attend the opera chiefly on account of the spectacle; whereas, in regard to gastronomic delights it is safe to say that at least two-thirds of our enjoyment is due to the sense of smell." (Henry T. Fincks, [1], p. 680)
Correspondence: charles.spence@psy.ox.ac.uk

${ }^{1}$ Crossmodal Research Laboratory, Oxford University, Oxford, UK

${ }^{2}$ Department of Experimental Psychology, University of Oxford, Oxford OX1 3UD, UK

\section{Biomed Central}

\section{Review}

One of the most pervasive claims in the food science literature, as well as in press articles about food and flavour, is that between 75 and $95 \%$ of what we think of as taste (i.e. as transduced by the gustatory receptors on the tongue), actually results from the stimulation of the olfactory receptors in the nose instead. In this article, I trace the history of this claim and assess whether it is even possible to provide an exact answer to the question of how much of what we think of as the taste of food and drink actually derives from the sense of smell. While returning a negative answer to this question, I nevertheless suggest that (while not taking the precise value too seriously) most informed commentators do seem to agree that olfaction plays a dominant role in our perception and enjoyment of food and drink. The problem here, then, is the seeming (and, in my view, unjustified) precision that the purveying of such figures conveys to 
the wider public. Nevertheless, broadening public awareness of olfaction's role in flavour perception is important, given that awareness of this fact can, and in some cases already is, changing the way in which chefs and culinary artists (especially those of a modernist persuasion) are thinking about their food delivery and multisensory experience design (see [2], for a number of intriguing examples). ${ }^{1}$

\section{On the prevalence of the claim}

Below, I include a selection of the claims regarding the importance of smell to what is commonly called taste from the popular psychology press, from peer-reviewed scientific research articles, and from the media, that I have come across in recent years (arranged chronologically). Notice how the precise value attributed to the relative contribution of the nose fluctuates between 75 and $95 \%$. Unfortunately, none of the quotes reference a specific source article in support of the claim they make, hence making it difficult, if not impossible, to perform a citation search (cf. [3]). However, the fact that (as far as I am aware) this claim first appears in Lyman's 1989 [4] popular science book $A$ psychology of food, more than a matter of taste is consistent (at least chronologically) with the suggestion that the source article for all claims of this sort was Murphy, Cain, and Bartoshuk's article published in Sensory Processes in 1977 [5]:

"Only about 10 percent of what we think of as taste is actually taste." ([4], p. 64)

"As much as $80 \%$ of what we call 'taste' actually is aroma" (Dr. Susan Schiffman quoted in the Chicago

Tribune, 3rd May, 1990; cited in [6])

"...about 80 per cent of food flavour is down to smell." ([7], p. 20)

"Ninety percent of what is perceived as taste is actually smell" (Dr. Alan Hirsch of the Taste Treatment and Research Foundation in Chicago, quoted in MX, Melbourne, Australia, 28 January 2003; cited in [6]). "If people are asked to select which sense they find least important, the sense of smell is routinely regarded as the least important of the five (Martin, 1999; Martin et al, 2001). It is, in fact, responsible for 80 per cent of food flavour, a fact that is largely unknown and elicits a degree of disbelief." ([8], p. 60) "90 percent of flavour derives from smell" [9]

"According to Dr Alan Hirsch of the Taste Treatment and Research Foundation in Chicago, $90 \%$ of what is perceived as taste is actually smell." [10]

"Up to $80 \%$ of what we consider taste is actually smell, said Andrea Burdack-Freitag" [11]

"The integration of smell with taste is so complete that, by some estimates, nearly 80 percent of a food's flavour is determined by its retronasal odor: This is consistent with neurophysiological research showing that odor and flavour inputs converge on brain regions related to your experience of taste." ([12], p. 114)

"According to researchers in nutrition science, between $80 \%$ and $90 \%$ of all sensations stimulating our appetite come from fragrances. Without these aromas, your morning bread and strawberry jam would be bland and tasteless!!” ([13], p. 35)

"Eighty per cent of what we think of as taste actually reaches us through smell,' says Barry Smith, co-director of the Centre for the Study of the Senses at the University of London." [14] ${ }^{2}$

"Many professionals I talked to gave me their own estimates for how much input our sense of taste provides. Some say that only about 5 percent of what we experience when eating is input from our sense of taste. They think that the remaining sensory input - the vast majority - is aroma, which we detect with our nose. Yes, most of what you think you taste is actually smell." ([15], p. 29) ${ }^{3}$

"Scientists believe that between 75 and 95 percent of what we 'taste' is actually smell." ([15], p. 56)

"75 per cent of what we perceive to be taste is actually smell" [16]

"It's astonishing that this fact is essentially unknown. Ninety-five percent of what we perceive as taste is in fact smell. Ninety-five percent of what we think we're tasting on the tongue we are actually registering in the olfactory receptors of the nasal epithelium (which sits just behind the bridge of our noses)."

(Chandler Burr, quoted in [17] $)^{4}$

\section{So, what's the problem with such explicitly quantitive statements?}

But what, exactly, is the problem with the use of such explicitly quantitative statements? And are there important differences between the claims being made? Just what would be lost (or gained) by replacing all those percentages with more descriptive, qualitative terms such as "a majority", "dominant", "most important", or "most critical"? Sivak ([3], p. 1082), I think, nicely highlights the issue here when he says of the analogous claim that $90 \%$ of driving is visual: "In our intellectual commerce, numbers have come to occupy a unique and influential position. When an author invokes the precision and power of numbers, the audience is led to believe that careful empirical work has been done to derive the values being presented, and that careful theoretical analysis has been done to construct a system of measurement that supports the validity of the numbers. Numbers are therefore persuasive. They can be expected to engender both in lay people and in specialists a sense of respect that, even when tempered by scepticism, is greater than respect accorded to mere qualitative descriptions. Therefore, when one opts to use 
numbers, one incurs a greater responsibility to provide evidence than if one uses a less quantitative estimate. In the case of the aforementioned claims, the issue is not whether the correct percentage is 90 versus perhaps 92 or 88 , but whether it is anywhere near 90 , as opposed to near 50 , for example." Indeed, in the absence of robust empirical evidence, one might even choose to side with those at the other end of the spectrum who downplay smell's role in flavour and feeding. As an example, just take the following quote from Havelock Ellis spotted by Avery Gilbert [18]: "If the sense of smell were abolished altogether the life of mankind would continue as before, with little or no sensible modification, though the pleasures of life, and especially of eating and drinking, would be to some extent diminished." ([19], pp. 47-48). Here, though, it is perhaps important to stress that the focus in this piece is on flavour perception rather than the entire multisensory eating experience where the sensory balance is undoubtedly quite different [2].

The final conclusion that Sivak ([3], p. 1083) draws from his research is perhaps also worth quoting, since it might well be considered to apply to the "75-95\% of taste is smell" claim as well: "None of the publications that contain claims such as ' $90 \%$ of driving-related information is visual' provides any supporting evidence. For the publications that cite other publications in support of such claims, the finding is the same: the final publications in the citation trees offer no supporting evidence. The implication is that we researchers have been (a) too lax about citing others, without checking for supporting evidence, and (b) too eager to appear more quantitative than the evidence allows."

\section{Not the only questionable fact out there!}

The $75-95 \%$ claim is certainly not the only seemingly precise, yet unsupported, statement that one finds in the psychological literature. As indicated above, Sivak [3] has done a great piece of detective work figuring out the history, and citations trees, underlying the claim that $90 \%$ of driving is visual in the ergonomics literature. As so often turns out to be the case, though, when one eventually traces these things back to their roots, the original authors cited in support of this particular figure, never said quite what everyone since has quoted them as saying! A little closer to the theme of the present article, another claim that is often made in the literature on the chemical senses is that there are 30,000 smells. In the introductory chapter to his excellent book, What The Nose Knows, Avery Gilbert attempts to trace the origin(s) of this claim. Once again, the underpinning data needed to support such a claim is, in fact, simply not there. ${ }^{5}$ In his words: "In the end, it appears that no one has ever attempted to count how many smells there are in the world. Estimates of odor diversity lead either to a dead end or to Ernest C. Crocker.
The comfortable, often-cited figure of 10,000 smells is, from a scientific perspective, utterly worthless." ([18], p. 4). In fact, as reported by scientists last year in Science, the true figure (in terms of the number of discriminable smells) may be much closer to one trillion ([20]; see also [21])!

The underlying concern here, then, is that the "75-95\% of taste comes from smell" claim is just another one of these "medical myths" [22] that we have all seen perpetuated in the popular press, but which turn out, on closer inspection, to have little or no basis in scientific fact. Take, for example, the assertion that we only use $10 \%$ of our brain, a claim has been in the literature for more than a century now (see [23], on the history). However, the statement has absolutely no basis in scientific fact $[22,24,25]$. As neurologist Barry Gordon at Johns Hopkins School of Medicine in Baltimore puts it, "the ' 10 percent myth' is so wrong it is almost laughable" [26]. Could the same be said of the 75-95\% claim? The fact that the various claims listed above do not cite a reputable source is not necessarily problematic if one can find solid empirical data to support such a claim.

To recap, from what we have seen thus far, I would be tempted to argue that the key potential problem with the claim that $75-95 \%$ of taste comes from the nose is that such precise, quantitative claims suggest a degree of certainty and scientific rigour that may simply not be warranted. It also serves to mask the underlying confusion amongst scientists and philosophers concerning how best to define taste and flavour [27].

\section{Evaluating the claim: some challenges}

So just how much truth is there in claims that somewhere between 75 and $95 \%$ of taste comes from the nose? Anyone wishing to evaluate the veracity of such statements faces a number of substantial challenges:

(1) Foremost amongst these challenges is the fact that no one can agree on quite how to define flavour (see [27-29]). Part of problem here is to discriminate between sensory inputs that merely modulate taste and those that are constitutive of it [30, 31]. As Bakelar ([32], p. S4) put it in the science journal Nature a few years back: "The way we experience food is not limited to the mouth-odour, vision, hearing and even touch can radically change the taste of food or affect food preference". Sure, vision and hearing can radically change the perceived taste of food and drink, but that does not necessarily mean that they should be deemed as constitutive of it. Until we know which senses are, in fact, constitutive of flavour, and which should be excluded (because they are merely modulatory), it is obviously going to be rather difficult to assign a precise contribution of each one to the overall flavour experience. ${ }^{6}$ 
Perhaps the best place for anyone wishing to start is with the International Standards Organization's definition of flavour as a: "Complex combination of the olfactory, gustatory and trigeminal sensations perceived during tasting. The flavour may be influenced by tactile, thermal, painful and/or kinaesthetic effects" [33, 34]. Now, while not everyone agrees with this narrow definition (see [35]), one might nevertheless still want to ask, at least as a starting point, whether the $75-95 \%$ claim can be supported relative to this particular definition of flavour. However, as we will see below, things are still not going to be easy for a number of reasons.

(2) The relative contribution of the senses to our experience and enjoyment of food and drink would seem to vary quite considerably depending upon the particular food that is under consideration. As Martin Yeomans puts it "any generalization about the degree to which any one sense contributes to food flavor is to some extent meaningless, since foods engage unique combinations of the key sensory systems" ([36], p. 800). The olfactory contribution of sushi, say, seems to be much lower than its contribution to our enjoyment of a ripe French cheese. Furthermore, the trigeminal contribution is much more pronounced for certain flavours/foods than for others-just think of the astringent tannins in a young oaked red wine or less prosaically, an overstewed cup of black tea.

Trigeminal chemical irritation, sometimes called "chemesthesis" [37] gives rise to a variety of everyday flavour experiences including "the fizzy tingle from $\mathrm{CO}_{2}$ in soda, the burn from hot peppers, black pepper, and spices such as ginger and cumin, the nasal pungency of mustard, horseradish, the bite from raw onions and garlic, not to mention their lacrymatory effects, to name a few. This important chemical sense is easily overlooked in considerations of taste and smell, because it has received less experimental study than the classical taste and smell modalities." ([38], p. 328). ${ }^{7}$

However, matters soon become complicated here for as Lawless ([38], p. 326) notes "Of course, this set of nerves [referring here to the trigeminal nerves] also mediates tactile, thermal, and pain sensations, so the distinction between a chemical sense and a tactile sense becomes blurred somewhat. This blurring is perhaps worst in the sensations of astringency. Tannins in foods are chemical stimuli [hence meaning that they are constitutive of flavour], and yet the astringent sensations they produce seem largely tactile [which would imply that they were merely modulatory]. They make the mouth feel rough and dry, and cause a drawing, pucker, or tightening sensation in the cheeks and muscles of the face (Bate Smith, 1954). Although scientific analysis would categorize astringency as a group of chemically induced oral tactile sensations, most wine tasters would say that astringency is an important component of wine 'flavour." In other words, it is not always such an easy matter to determine whether a particular component of our flavour experiences should be treated as constitutive or merely modulatory. Should the decision be based on the physiology or the phenomenology? The jury, it should be said, is still out here.

Given such concerns, one could, of course, retreat still further, and just take the case of flavours that have no obvious trigeminal component. In such cases, one could ask whether, using the ISO definition of flavour, the 75$95 \%$ claim can be supported. However, as we will see below, even in such a restricted case, we run into problems. In particular, because the relative contribution of smell to taste/flavour ${ }^{8}$ perception depends crucially on the particular combination of (taste and smell) stimuli involved. It is at this point in our discussions, though, that it may be worth looking a little more closely at what is likely the underpinning research that inspired many of the claims one finds nowadays in the literature.

(3) I would argue that the original, and as far as I can tell, only research that has, on occasion, been cited in support of the 75-95\% claim simply does not support the assertion, or perhaps better said, only supports a very narrow version of the claim. Specifically, Murphy et al. [5] conducted a study in which they demonstrated that the perceived intensity of a solution containing both a tastant (sodium saccharin) and an odorant (ethyl butrate) was roughly equivalent to the sum of the perceived intensity of the component stimuli when presented individually. Crucially, however, the six participants (trained panellists) in this study attributed approximately $80 \%$ of the intensity of the ensuing mixture to the sense of taste.

More specifically, the participants were given a series of solutions to taste, and they had to rate the intensity of the odour, the taste, or the overall solution using a magnitude estimation procedure. The participants were given solutions containing only the tastant, solutions containing only the odorant, and solutions containing a mixture of the two. Intensity ratings for the mixture were slightly lower than would have been expected based on the summed response to each of the putatively unisensory stimuli. Interestingly, however, when the participants rated the mixed solution while their nose was closed, their ratings dropped by $80 \%$ when compared to their judgments with their nose open. Here, it is worth quoting at length, 
the passage from Murphy et al. that may well have triggered all those $75-95 \%$ claims in the subsequent years: "An examination of how subjects apportioned their judgments into the categories odor and taste revealed the existence of taste-smell confusions. Subjects ascribed little odor magnitude to solutions containing only sodium saccharin, but ascribed considerable taste magnitude to solutions containing only ethyl butrate. The taste ascribed to ethyl butrate was not due exclusively to its action on gustation since, when the nostrils were closed, as much as $80 \%$ of the "taste" disappeared. Subjects seem to resolve ambiguity regarding the locus of mutual olfactory-taste stimulation in favour of taste." (Murphy et al. [5], p. 204).

It is at this point that questions about the particular combination of olfactory and gustatory stimuli used become relevant [39]. Murphy et al. used ethyl butrate which is a particularly sweet-smelling odorant [40]. Stevenson and his colleagues have shown that certain odours, such as, for example, a caramel odour could simultaneously enhance sweetness while at the same time suppressing sourness ([41]; see also [39]). ${ }^{9}$ Hence, the relative contribution of olfaction and gustation to a tasting experience is crucially going to depend on how regularly the component stimuli have been experienced together previously. One suggestion is that it is only when the olfactory and gustatory stimuli are congruent, i.e. ecologically valid-that one gets a flavour experience, more or less (see [42]). In other words, it may only be under conditions of oral referral that we believe that smell is contributing significantly to the tasting experience that is flavour perception. Interestingly, the extent of oral referral to the mouth depends on the congruency between the olfactant and the tastant $[42,43]$. The suggestion, then, that has been made by commentators is that the effect reported in Murphy et al.'s [5] study likely resulted from the misattribution of the "sweet" component of the olfactory stimulus to the taste system, due to the well-known referral of the odour to the oral cavity ([42-47]).

(4) Are we talking about orthonasal olfaction (i.e. sniffing), retronasal olfaction, or the combined influence of the two senses of smell (see $[1,45])$ ? The former certainly plays an important role in the setting of taste and flavour expectations $[48,49]$, and hence plays only a modulatory role, while the latter is thought to be constitutive of flavour experiences. Importantly, however, these two types of olfaction recruit somewhat different neural substrates when it comes to the representation and processing of food odours [50]. What is more, they also have somewhat different behavioural/perceptual correlates [45, 51, 52].
One can, I think, take the ISO definition of "olfaction .... during tasting" to be referring specifically to the retronasal case. It is ironic, then, that the Murphy et al. [5] study that gave rise to the 75-95\% claim may actually have involved contributions from both orthonasal and retronasal aroma. ${ }^{10}$ As such, the claim would seem to be based on research involving the contribution of both modulatory (orthonasal olfaction) and constitutive cues (retronasal olfaction) to flavour. Sure, this is the way in which we normally experience foods in our everyday lives, but returning to the point made earlier, it reopens, I think, the debate about which senses really belong in one's definition of flavour.

(5) There is frequently also a confusion between the layman's use of the term taste and that of the professional. As McBurney ([27], p. 118) puts it: "The layperson uses the term taste to refer to sensations that professionals carefully distinguish as taste, smell, or flavour. Although this permits us to point out smugly that the layperson's use of the word taste fails to account for the symphony of senses used in "tasting" something, the layperson is simply unreflective following Gibson's (1966) important notion of the senses as perceptual system that makes use of many separate senses, including taste, smell, the common chemical sense, temperature, touch, vision and hearing ("They taste as good as they crunch"). All of these contribute to flavour." On the one hand, then, in our everyday language, we all tend to confuse the terms "taste" and "flavour". ${ }^{11}$ After all, every one of us says that we enjoy the taste of the food, when what we really mean to say is that we enjoy its flavour. As Bartoshuk and Duffy ([53], p. 27) note: "Taste' is often used as a synonym for "flavour". This usage of 'taste' probably arose because the blend of true taste and retronasal olfaction is perceptually localized to the mouth via touch". The fundamental problem here then is that "Ordinary people do not appear to treat tastes and smell from the mouth as different kinds of sensation (Lawless, 1996)." ([40], pp. 72-73). As Barry Smith [54] notes "Although we're all familiar with taste, it is surprisingly complex and puzzling."12

Authors also sometimes switch back and forth between different meanings of the term taste, adding further to the confusion. Just take, for instance, Korsmeyer's ([55], p. 3) introduction in her edited volume, The Taste Culture Reader, where one finds the following: "Except where otherwise specified, the word 'taste' in this book serves as a shorthand for the experience of flavor in all its dimensions, including those supplied by the other senses." So 
far, so good. But then Korsmeyer goes on to say that: "Not all flavours can be classified according to the four 'basic' types, \& some of the most sought-after tastes are spices..." ([55], p. 5). This is where I start to become confused. By the four basic types, Korsmeyer presumably means the four basic tastes-namely, sweet, sour, salt, and bitter (though note that umami is now regularly being included in lists of the basic tastes). ${ }^{13}$ By contrast, flavours, at least as commonly understood, include many of the more interesting qualities of food, think fruity, floral, herbal, meaty, burnt, smoky, etc. A similar potential for confusion could easily occur for anyone reading the title of McLagen's [56] recent volume, Bitter: A taste of the World's Most Dangerous Flavour, With Recipes. It is only hidden away on page 3 that the author acknowledges that she intends to use the terms taste and flavour interchangeably. In order to give a precise estimate of what percentage of taste comes from the nose, then, one needs to know exactly what the writer means by the term "taste".

The fact that certain olfactory stimuli, such as vanilla, caramel, or strawberry aromas for those in the west, can also modulate, or perhaps even give rise to, the perception of sweetness in an otherwise tasteless solution puts pressure on the definition of taste [40]. In this case, a person might have a flavour experience with a distinctive taste component even though no tastant was actually present (though some tactile stimulation would likely be needed in the oral cavity to give rise to the requisite oral referral to the mouth). Pressure on one's definition also comes from the fact that taste receptors are also found in the gut, genitalia, in sperm, etc $[57,58]$. I would like to argue that Rozin's ([45], p. 398) definition: "Technically, the designation 'taste' should be used as a total perceptual description for only the pure gustatory properties (e.g. sweet, salt, sour, bitter), for combinations of gustatory qualities, and for substances that produce these sensations in the absence of salient olfactory or nongustatory oral sensations. Examples would be sugar and salt." now needs updating. In particular, given recent evidence concerning the existence of cells with taste receptors in the gut, respiratory and gastro-intestinal tracts, and elsewhere (see $[57,58]$ ), the definition should also stipulate that stimulation of the gustatory receptors in the oral cavity is required [59]. Typically, taste is a conscious experience, and one that is localized to the mouth, though such criteria probably do not belong in one's definition (see also [60] for the use of illusion to take taste out of the mouth).

(6) What role attention? In many areas of our daily lives, what we perceive (and are aware of) depends fundamentally on where our attention happens to be directed, either endogenously (voluntarily) or exogenously (i.e. in a stimulus driven manner; $[61,62])$. Is the same true when it comes to the perception of taste/flavour? If so, the percentage of taste that is contributed by smell might be expected to vary as a function of the attentional state of the observer. Stevenson [63] has been doing some of the most detailed thinking in this area. However, flavour binding would appear to make it especially difficult for people to covertly attend [64] to just one element of an integrated flavour gestalt $[65,66]$. Indeed, this inability to pull apart sensations based on attention has also been stressed by Smith [67].

(7) One final source of evidence that would seem potentially relevant to this debate concerns the consequences of the absence of sense of taste (gustation) or smell (olfaction) on multisensory flavour perception. In the case of olfaction, the absence of olfactory sensation (what is known as anosmia) can either be congenital [68] or acquired (i.e. late-onset) [69]. By contrast, I am not aware of any congenital form of aguesia. In those cases of late-onset taste loss, resulting from the removal of the tongue [70] or following herpes [71], those so affected have reported surprisingly little loss of sensation (though see also [72] for a chef who lost the ability to taste following treatment for tongue cancer). When it comes to anosmia, the results would appear to depend on when exactly the loss occurred. Congenital anosmics appear to adapt reasonably well, whereas when the loss of smell occurs later in life (typically the result of car accident or viral infection) appear to dramatic changes in food appreciation [73]. The answer may also change somewhat as a function of how far into a meal one is as well, given possible consequences of olfactory loss for sensory-specific changes in satiety ([74]; though see also $[75,76])$. Studying those individuals suffering from a selective loss of trigeminal sensation would also, potentially, be interesting here. It is, however, important to note that drawing any simple conclusions here concerning the relative importance of smell and taste to flavour perception, based on the loss of one of the flavour senses, is made all the more difficult by the cortical plasticity that may occur in such cases $[67,77]$.

\section{Conclusions}

In conclusion, explicitly quantitative claims that somewhere between 75 and $95 \%$ of what is commonly considered as taste really rely on the information transduced by the nose are widespread in the literature, both academic and popular, on food science and flavour perception. However, in the majority of such cases, no specific evidence is cited in support of the claim. What is more, the 
only article that is, on occasion, cited-specifically, Murphy et al. [5] - fails to provide the kind of support that is needed to robustly support such statements. In fact, I would be tempted to argue that it is pretty much meaningless to try and put a precise value, or even a narrow range of values, around the relative contribution of olfactory cues to multisensory flavour perception. ${ }^{14}$ The reasons being that it will likely depend substantially on the food or stimuli presented and one's own definition of which senses are constitutive of flavour and which are merely modulatory. Given that there is little consensus regarding quite how flavour should be defined (specifically regarding which of the senses play a constitutive and which a merely modulatory role) delivering a precise verdict is some way off yet and would anyway carry with it a whole host of assumptions.

Researchers should, then, perhaps be more cautious about propagating such explicitly quantitative but unsubstantiated (and possibly unsubstantiable) claims (see also [78]). As Sivak ([3], p. 1088) winds up concluding in his review of the "90\% of driving is visual" claim: "The lack of direct evidence for the ' $90 \%$ ' claims provides a lesson for all of us researchers. Most of us have been guilty, at one time or another, of citing another person's conclusion without assuring ourselves that the conclusion is supported by convincing evidence. By verifying what we cite we would minimize the chances that unjustifiable but plausible claims become enshrined in the literature." So, then, rather than attempting to provide such quantitative statement on the matter, we should all perhaps opt for a rather more cautious wording. To give you one idea of what I have in mind here, just take the following suggestion from Martin Yeomans in one of his papers of a decade ago: "it is generally recognized that olfactory stimuli contribute a significant proportion of the experience of flavors for the majority of foods." ([36], p. 800). Here, though, we should also not forget the role of the gustatory system in visceroception, interoception, and hedonia (although coded in a more subconscious way; [79]).

Nevertheless, even without being able to put a precise value on the contribution of olfaction (both orthonasal and retronasal one presumes) to our expectations and experience of food and drink, most researchers do seem happy to agree that the pleasure, all the interesting dimensions of what is commonly called taste, the meaty, the floral, the fruity, the herbal, the citrus, the burnt, all derive primarily from the contribution of olfaction. ${ }^{15}$

Thus, as I hope to have made clear in this opinion piece, trying to assign a precise value to the role of any one of our senses in our perception and/or enjoyment of eating and drinking is an exceedingly tricky business. And this is perhaps never more challenging than when it comes to weighing up the relative contributions of the constitutive flavour senses of gustation, retronasal olfaction, and trigeminal stimulation. Nevertheless, it seems true to say that the claim that $75-95 \%$ of taste comes from the nose captures a sentiment that most people will share-at least once they have taken the jelly bean test [80].

Ultimately, though, no matter whether or not we have a precise percentage to support it, widespread belief in the dominant role that olfactory cues play both in the anticipation of, as well as our experiences on, consuming food and drink if often under-acknowledged part of the entire flavour/meal experience. As such, publicizing olfaction's key role may, in the future, help to foster a somewhat different approach to the delivery of food and beverage experiences [81]. Indeed, awareness of olfaction's dominant role in flavour perception and in the enjoyment of food and drink might, for example, lead the chef to think a little differently about the design of their culinary creations: thinking, for example, how best to ensure that as much of the aroma of a dish reaches the noses of their diners as possible. The work of a number of modernist chefs, culinary artists, and designers in recent years can be seen as playing in precisely this space (see [2, 72], for a number of such examples). Here, think only of such developments as the Aromafork from Molecule- $R$ [82], the olfactory plateware introduced by chefs such as Grant Achatz at Chicago's Alinea (see [2], those delivering so-called scent dinners; e.g. [17]), and even the use of atomizers to deliver fragrance/aroma to a dish, as repopularized recently by the likes of Heston Blumenthal [83] and London-based chef, Jozef Youssef (see https://kitchen-theory.com/). ${ }^{16}$

\section{Endnotes}

${ }^{1}$ So, for instance, a growing number of chefs have started to deliver an olfactory component to their dishes through the use of aromatic plateware, through the use of atomized sprays over a dish. A number of chefs, culinary artists, and companies have also started to deliver an additional aromatic element to a dish through the use of scent-enabled cutlery (see [81] for additional examples).

${ }^{2}$ Of course, one of the problems here is with the way in which the press abbreviate what the academic says. As an academic talking to a journalist (and here I speak from personal experience), one might well say something like: "It is often said that $80 \%$ of what we think of as taste...", a statement which is a perfectly accurate summary of the literature (and which panders to the media's desire for percentages). The initial "It is often said that" being the scientist's way of distancing him-or herself from the claim, given the difficulty, as we will see below, of ever coming up with such a precise value. However, 
the ensuing article will typically abbreviate the quote to read Prof. X say that " $80 \%$ of what we think of as taste ..." Now this is not what the Prof. said at all, or at least, it is very definitely not what was meant. Nevertheless, there is a very real danger that this is the quote that will be attributed to him/her in the popular press. Prof. Smith assures me (personal communication) that he indeed prefaced his statement to The Financial Times in this way.

${ }^{3}$ At one level, such claims would seem to contradict the results of a survey of 140 food industry professionals reported by Delwiche [84], in which 96 and $94 \%$ of those questioned rated taste and smell, respectively, essential to flavour.

${ }^{4}$ Note that this is by no means meant to be an exhaustive listing. There are many other examples of a percentage being given in academic and popular press articles: there are many more examples of commentators suggesting (asserting?) that smell is responsible for 75 (according to [85, 86]) or $80 \%$ (according to [87]) of taste.

${ }^{5}$ Leading Gilbert ([18], p. 2) to conclude that "dubious facts thrived in the media long before the internet."

${ }^{6}$ Stuckey ([15], p. 29) also highlights the importance of being clear in specifying exactly which senses one is considering as contributing to flavour: "I think 10 percent for taste and 90 for smell is a better estimate, but only if you're dividing the entire experience of eating between just the two senses of taste and smell. What about the other three? When you add the influence of touch, hearing, and sight, things get really interesting."

${ }^{7}$ While helpful, there are a couple of points to note about Lawless's suggestions here. First, while I accept that crying in response to the sting of the onion is mediated by the trigeminal system, I am not so sure I want to call it part of the flavour experience. Second, and highlighting the complexity associated with working and theorizing in this area, while carbonation was traditionally considered primarily a trigeminal stimulant (e.g. see $[88,89])$, research that has been published subsequent to Lawless's review, in fact, suggests that the experience of carbonation in a fizzy drink is actually mediated by the sour-sensing receptors together with stimulation of the somatosensory system (see [90]). And confusing matters still further, Di Salle et al. [91] have recently demonstrated that carbonation can affect (suppress) the brain's processing of sweet-tasting stimuli, especially sucrose.

${ }^{8}$ It should be noted, in passing, that in many languages, the same term is used for both taste and flavour. Rozin [45] notes that languages that use the same word include Spanish (Cuban; "sabor"), German ("geschmack"), Czech ("chut"), and Chinese mandarin ("wei").

${ }^{9}$ The suggestion being that such effects result from prior learning of specific flavour-taste associations in foods (e.g. see [40]).
${ }^{10}$ While the methodological details in the original article are not sufficiently clear on this point, it would seem most likely from the description given that participants first sniffed the solutions that they were given to taste before swallowing them, given the instruction "to appreciate both odor and taste in the same way that they would appreciate the bouquet and taste of wine" ([5], p. 204).

${ }^{11}$ Note here also that the concept that there are two senses of smell, orthonasal and retronasal, is also typically confusing, or surprising to the layperson. That, or so it has been suggested, is why they think of smell (referring to orthonasal) is not involved in tasting flavours.

${ }^{12}$ And this is before we get to the complexity that is introduced by the fact that we use the word taste to talk about aesthetic appreciation here [92].

${ }^{13}$ Indeed, some scientists believe that there may be 15-20 more basic tastes, such as metallic, fatty acid, and kokumi, that are awaiting their proper recognition $[15,93]$.

${ }^{14}$ As Stuckey ([15], p. 29) puts it: "Taste, taste buds, and the tongue represent a tiny amount of what you experience when you eat food. ... There's absolutely no way to prove how much information the tongue contributes."

${ }^{15}$ And anyone who has tasted a mixture of the basic tastes at a near-threshold level knows how strange and empty an experience it is.

${ }^{16}$ The first use of atomizers to spray perfume over the diner was possibly being reported by the Italian Futurists (see [94], p. 43; see also [81]).

\section{Competing interests}

The author declares no competing interests.

\section{Author's contributions}

CS wrote all of this review.

\section{Acknowledgments}

CS would like to acknowledge helpful comments from Prof. Barry Smith on an earlier draft of this paper, and the AHRC Rethinking the Senses grant (AH/L007053/1).

\section{Received: 28 July 2015 Accepted: 5 October 2015}

Published online: 02 November 2015

\section{References}

1. Fincks HT. The gastronomic value of odours. Contemp Rev. 1886;50:680-95

2. Spence C, Piqueras-Fiszman B. The perfect meal: the multisensory science of food and dining. Oxford, UK: Wiley-Blackwell; 2014

3. Sivak M. The information that drivers use: is it indeed $90 \%$ visual? Perception. 1996;25:1081-9.

4. Lyman B. A psychology of food, more than a matter of taste. New York, NY: Avi, van Nostrand Reinhold; 1989.

5. Murphy C, Cain WS, Bartoshuk LM. Mutual action of taste and olfaction. Sens Processes. 1977;1:204-11.

6. Jacob T. Smell (olfaction): a tutorial on the sense of smell. Available at http://163.178.103.176/Fisiologia/neurofisiologia/Objetivo_2/olfact1.html. Accessed 27 July 2015.

7. Martin GN. For dangerous roads, keep a sweet bouquet handy. Times Higher Educ Suppl. 2001;July 27:20. Available at https:// www.timeshighereducation.co.uk/features/for-dangerous-roads-keep-asweet-bouquet-handy/164093.article. 20 July 2015.

8. Martin GN. A neuroanatomy of flavour. Petits Propos Culinaires. 2004;76:58-82. 
9. Walters J. Heaven-scent diet. London Evening Standard. 2004.

10. Griffiths SC. Taste without smell: what does the lack of a sense of smell do to flavour perception? And what sounds and sights get your juices flowing? The Guardian, Food \& Drink, Word of Mouth blog. 2008. Available at http://www.theguardian.com/lifeandstyle/wordofmouth/2008/jul/21/ anosmiasensetaste. Accessed 14 July 2015.

11. Michaels D. Test flight: Lufthansa searches for savor in the sky. Wall Street J. 2010. Available at http://online.wsj.com/article/SB1000142405274870329 4904575384954227906006.html. Accessed 14 July 2015.

12. Rosenblum LD. See what I am saying: the extraordinary powers of our five senses. New York: W. W. Norton; 2010.

13. Chartier F. Taste buds and molecules: the art and science of food, wine, and flavor (translated by Levi Reiss). Hoboken, NJ: John Wiley and Sons; 2012.

14. Ge L. Why coffee can be bittersweet. FT Weekend Magazine. 2012; October 13/14:50

15. Stuckey B. Taste what you're missing: the passionate eater's guide to why good food tastes good. London, UK: Free Press; 2012.

16. Pilkington D. Losing your sense of smell can make you fat-and destroy your libido too! Daily Mail Online. 2014. Available at http://www.dailymail.co.uk/health/article-2639914/Losing-sense-smell-makefat-destroy-libido-too.html. 14 July 2015.

17. Koutsovoulou E. Chandler Burr: "take your seat to a scent dinner". Fine Dining Lovers. 2014. Available at https://www.finedininglovers.com/stories/ chandler-burr-interview-scent-dinner/. Accessed 20 July 2015.

18. Gilbert A. What the nose knows: the science of scent in everyday life. New York, NY: Crown; 2008

19. Ellis H. Studies in the psychology of sex: sexual selection in man. Philadelphia: FA Davis Company; 1922.

20. Bushdid C, Magnasco MO, Vosshall LB, Keller A. Humans can discriminate more than 1 trillion olfactory stimuli. Science. 2014;343:1370-2.

21. Briggs H. Nose can detect one trillion odours. BBC News Online 2014; 20th March. Downloaded from http://www.bbc.com/news/health-26638085 on 28/10/2015.

22. Vreeman RC, Carroll AE. Medical myths. BMJ. 2007;335:1288-9. http://dx.doi.org/10.1136/bmj.39420.420370.25.

23. Beyerstein BL. Whence cometh the myth that we only use $10 \%$ of our brains? In: S Della Sala, editor. Mind myths: exploring popular assumptions about the mind and brain. New York, NY: Wiley. 1999; 3-24.

24. Jha A. Heard the one about reading in dim light being bad for your eyes? It's just a myth. The Guardian. 2007. Downloaded from http://www.theguardian. com/science/2007/dec/21/medicalresearch on 28/10/2015.

25. Spencer B. Myth that we use just $10 \%$ of our brains: Scientist says entire organ is in use all the time because nerves cells involved in thought are always active. Daily Mail Online. 2014. Available at http:// www.dailymail.co.uk/sciencetech/article-2699481/Myth-use-just-10-brainsScientist-says-entire-organ-use-time-nerves-cells-involved-thoughtactive.html. Accessed 19 July 2015.

26. Boyd R. Do people only use 10 percent of their brains? What's the matter with only exploiting a portion of our gray matter? Sci Am. 2008. Available at http://www.scientificamerican.com/article/do-people-only-use-10-percentof-their-brains/. Accessed 14 July 2015.

27. Spence C, Smith B, Auvray M. Confusing tastes and flavours. In: Stokes D, Matthen M, Biggs S, editors. Perception and its modalities. Oxford, UK: Oxford University Press; 2015. p. 247-74.

28. McBurney DH. Taste, smell, and flavor terminology: taking the confusion out of fusion. In: Meiselman HL, Rivkin RS, editors. Clinical measurement of taste and smell. New York, NY: Macmillan; 1986. p. 117-25.

29. Spence C. Auditory contributions to flavour perception and feeding behaviour. Physiol Behav. 2012;107:505-15.

30. Smith BC. The nature of sensory experience: the case of taste and tasting. Phenomenology Mind Online J. 2013:292-313. Downloaded from on http:// www.phenomenologyandmind.eu/wp-content/uploads/2013/07/B.C.Smith.pdf 28/10/2015

31. Spence C. Multisensory flavour perception. To appear in C Korsmeyer (Ed.), The taste culture reader (2nd Ed.). Oxford, UK: Bloomsbury. in press.

32. Bakelar N. Partners in flavour. Nature. 2012;486:S4-5.

33. ISO Standard 5492. Terms relating to sensory analysis. International Organization for Standardization. Vienna: Austrian Standards Institute; 1992

34. ISO Standard 5492. Terms relating to sensory analysis. International Organization for Standardization. Vienna: Austrian Standards Institute; 2008

35. Spence C, Levitan C, Shankar MU, Zampini M. Does food color influence taste and flavor perception in humans? Chemosens Percept. 2010;3:68-84.
36. Yeomans MR. Olfactory influences on appetite and satiety in humans. Physiol Behav. 2006:87:800-4.

37. Green BG, Lawless HT. The psychophysics of somatosensory chemoreception in the nose and mouth. In: Getchell TV, Doty RL, Bartoshuk LM, Snow JB, editors. Smell and taste in health and disease. New York, NY: Raven; 1991. p. 235-53.

38. Lawless HT. Flavor. In: Friedman MP, Carterette EC, editors. Handbook of perception. Cognitive ecology. San Diego: Academic; 1996. p. 325-80.

39. Stevenson RJ, Boakes RA, Prescott J. Changes in odor sweetness resulting from implicit learning of a simultaneous odor-sweetness association: an example of learned synaesthesia. Learn Motiv. 1998;29:113-32.

40. Stevenson RJ, Boakes RA. Sweet and sour smells: learned synaesthesia between the senses of taste and smell. In: Calvert GA, Spence C, Stein BE, editors. The handbook of multisensory processing. Cambridge, MA: MIT Press; 2004. p. 69-83.

41. Stevenson RJ, Prescott J, Boakes RA. Confusing tastes and smells: how odours can influence the perception of sweet and sour tastes. Chem Senses. 1999;24:627-35.

42. Lim J, Johnson MB. The role of congruency in retronasal odor referral to the mouth. Chem Senses. 2012;37:515-21.

43. Lim J, Johnson MB. Potential mechanisms of retronasal odor referral to the mouth. Chem Senses. 2011;36:283-9.

44. Hollingworth HL, Poffenberger AT. The sense of taste. New York, NY: Moffat Yard; 1917.

45. Rozin P. "Taste-smell confusions" and the duality of the olfactory sense Percept Psychophys. 1982;31:397-401.

46. von Békésy G. Olfactory analogue to directional hearing. J Appl Physiol. 1964;19:369-73.

47. Murphy C, Cain WS. Taste and olfaction: independence vs. interaction. Physiol Behav. 1980;24:601-5.

48. Piqueras-Fizman B, Spence C. Sensory expectations based on productextrinsic food cues: an interdisciplinary review of the empirical evidence and theoretical accounts. Food Qual Prefer. 2015;40:165-79.

49. Stevenson RJ. The psychology of flavour. Oxford, UK: Oxford University Press; 2009.

50. Small DM, Gerber JC, Mak YE, Hummel T. Differential neural responses evoked by orthonasal versus retronasal odorant perception in humans. Neuron. 2005:47:593-605.

51. Diaz ME. Comparison between orthonasal and retronasal flavour perception at different concentrations. Flav Fragrance J. 2004;19:499-504.

52. Pierce J, Halpern BP. Orthonasal and retronasal odorant identification based upon vapor phase input from common substances. Chem Senses. 1996;21:529-43.

53. Bartoshuk LM, Duffy VB. Chemical senses: taste and smell. In: Korsmeyer C, editor. The taste culture reader: experiencing food and drink. Oxford, UK: Berg; 2005. p. 25-33.

54. Smith B. Perspective: complexities of flavour. Nature. 2012;486:S6.

55. Korsmeyer $\mathrm{C}$. The taste culture reader: experiencing food and drink. Oxford, UK: Berg; 2005.

56. McLagen J. Bitter: a taste of the world's most dangerous flavour, with recipes. London, UK: Jacqui Small LLP; 2015

57. Trivedi B. Hardwired for taste: research into human taste receptors extends beyond the tongue to some unexpected places. Nature. 2012;486:S7.

58. Finger TE, Kinnamon SC. Taste isn't just for taste buds anymore. Biol Rep. 2011;3:20.

59. Scott K. Taste recognition: food for thought. Neuron. 2005;48:455-64.

60. Michel C, Velasco C, Salgado A, Spence C. The butcher's tongue illusion. iPerception. 2014;3:818-24.

61. Driver J. A selective review of selective attention research from the past century. Br J Psychol. 2001;92:53-78.

62. Posner MI. Chronometric explorations of mind. Hillsdale, NJ: Erlbaum; 1978.

63. Stevenson RJ. The role of attention in flavour perception. Flavour. 2012;1:2.

64. Spence C. Orienting attention: a crossmodal perspective. In: Nobre AC, Kastner S, editors. The Oxford handbook of attention. Oxford, UK: Oxford University Press; 2014. p. 446-71.

65. Spence C. Cross-modal perceptual organization. In: Wagemans J, editor. The Oxford handbook of perceptual organization. Oxford, UK: Oxford University Press; 2015. p. 649-64.

66. Stevenson RJ. Flavor binding: its nature and cause. Psychol Bull. 2014;140:487-510.

67. Smith B. Taste, philosophical perspectives. In: Pashler H, editor. Encyclopaedia of mind. San Diego, CA: University of California; 2013. p. 731-4. 
68. Hasan K, Reddy S, Barsony N. Taste perception in Kallmann syndrome: a model of congenital anosmia. Endocr Pract. 2007;13:716-20.

69. Croy I, Negioas S, Novakova L, Landin BN, Hummel T. Learning about the functions of the olfactory system from people without a sense of smell. PLoS One. 2012;7:e33365.

70. Brillat-Savarin JA. Physiologie du goût [The philosopher in the kitchen/the physiology of taste]. JP Meline: Bruxelles. Translated by A Lalauze (1884), A handbook of gastronomy. London: Nimmo \& Bain; 1835.

71. Pfaffmann C, Bartoshuk LM. Taste loss due to herpes zoster oticus: an update after 19 months. Chem Senses. 1990;15:657-8.

72. Anonymous: Grant Achatz: The chef who couldn't taste NPR 2011;29th August. Available at http://www.npr.org/2011/08/29/139786504/grantachatz-the-chef-who-couldnt-taste. Accessed 01 October 2015.

73. Mattes RD, Cowart BJ. Dietary assessment of patients with chemosensory disorders. J Am Diet Assoc. 1994;94:50-6.

74. Novakova L, Bojanowski V, Havlíček J, Croy I. Differential patterns of food appreciation during consumption of a simple food in congenitally anosmic individuals: an explorative study. PLoS One. 2012;7(4):e33921.

75. Seo HS, Hummel T. Effect of olfactory dysfunction on sensory evaluation and preparation of foods. Appetite. 2009;53:314-21.

76. Havermans RC, Hermanns J, Jansen A. Eating without a nose: olfactory dysfunction and sensory-specific satiety. Chem Senses. 2010;35:735-41.

77. Gagnon L, Kupers R, Ptito M. Making sense of the chemical senses. Multisens Res. 2014;27:399-419.

78. Pullum GK. The great Eskimo hoax and other irrelevant essays on the study of language. London, UK: University of Chicago Press; 1991.

79. Sewards K. Dual separate pathways for sensory and hedonic aspects of taste. Brain Res Bull. 2004;62:271-83.

80. Greenwood V. The real reason sweet tastes sweet. BBC Website; 2015. Available at http://www.bbc.com/future/story/20150610-the-smells-that-makesweet-sweeter?ns_mchannel=social\&ns_campaign=bbc_homepage\&ns_ source=twitter\&ns_linkname=corporate. Accessed 19 July 2015.

81. Spence C, Youssef J. Olfactory dining: designing for the dominant sense. Flavour submitted.

82. Bloom D. Revolutionary new fork that adds own flavour to each mouthful is the latest foodie gadget to hit the market. Daily Mail Online; 2014. Available at http://www.dailymail.co.uk/sciencetech/article-2587272/Revolutionarynew-fork-adds-flavour-mouthful-latest-foodie-gadget-hit-market.html. Accessed 05 November 2014.

83. Blumenthal H. The big Fat Duck cookbook. London, UK: Bloomsbury; 2008.

84. Delwiche JF. Attributes believed to impact flavor: an opinion survey. J Sens Stud. 2003;18:437-44.

85. Anonymous. The Viora lid unlocks the aroma of your beverage. Available at http://www.vioralid.com/benefits/the-viora-lid-unlocks-the-aroma-of-yourbeverage/. Accessed 10 September 2015.

86. Anonymous (2011). N.Y. grocery turns to scent marketing. CBS News July 18th. Available at http://www.cbsnews.com/news/ny-grocery-turns-to-scentmarketing/. Accessed 26 September 2015.

87. Tafalla M. A world without the olfactory dimension. Anat Rec. 2013;296:1287-96.

88. Carstens E, Cartsens MI, Dessirier JM, O'Mahony M, Simons CT, Sudo M, et al. It hurts so good: oral irritation by spices and carbonated drinks and the underlying neural mechanisms. Food Qual Prefer. 2002;13:431-43.

89. Dessirier JM, Simons CT, Carstens MI, O'Mahony M, Carstens E. Psychophysical and neurobiological evidence that the oral sensation elicited by carbonated water is of chemogenic origin. Chem Senses. 2000;25:277-84.

90. Chandrashekar J, Yarmolinsky D, von Buchholtz L, Oka Y, Sly W, Ryba NJP, et al. The taste of carbonation. Science. 2009;326:443-5.

91. Di Salle EC, Savarese MF, Aragri A, Prinster A, Nicolai E, Sarnelli G, et al. Effect of carbonation on brain processing of sweet stimuli in humans. Gastroenterol. 2013;145:537-9.

92. Brown S, Gao X, Tisdelle L, Eickhoff SB, Liotti M. Naturalizing aesthetics: brain areas for aesthetic appraisal across sensory modalities. Neuroimage. 2011;58:250-8

93. Extance, A. Fine flavours: the unsuspected talents of your taste buds. New Scientist 2015;5th August. Available at https://www.newscientist.com/article/ mg22730331-200-fine-flavours-the-unsuspected-talents-of-your-taste-buds/. Accessed 05 September 2015.

94. Marinetti FT, Colombo L. La cucina futurista: Un pranzo che evitò un suicidio [The Futurist kitchen: a meal that prevented suicide]. Milan: Christian Marinotti Edizioni; 1930/1998.

\section{Submit your next manuscript to BioMed Central and take full advantage of:}

- Convenient online submission

- Thorough peer review

- No space constraints or color figure charges

- Immediate publication on acceptance

- Inclusion in PubMed, CAS, Scopus and Google Scholar

- Research which is freely available for redistribution

Submit your manuscript at www.biomedcentral.com/submit 